\title{
Monolithic Microwave Integrated Circuits (MMIC) Broadband Power Amplifiers (Part 2)
}

\author{
by John E. Penn
}




\section{NOTICES}

\section{Disclaimers}

The findings in this report are not to be construed as an official Department of the Army position unless so designated by other authorized documents.

Citation of manufacturer's or trade names does not constitute an official endorsement or approval of the use thereof.

Destroy this report when it is no longer needed. Do not return it to the originator. 


\title{
Army Research Laboratory
}

Adelphi, MD 20783-1197

ARL-TN-0556

July 2013

\section{Monolithic Microwave Integrated Circuits (MMIC) Broadband Power Amplifiers (Part 2)}

\author{
John E. Penn \\ Sensors and Electron Devices Directorate, ARL
}




\begin{tabular}{|c|c|c|}
\hline \multicolumn{2}{|c|}{ REPORT DOCUMENTATION PAGE } & $\begin{array}{l}\text { Form Approved } \\
\text { OMB No. 0704-0188 }\end{array}$ \\
\hline \multicolumn{3}{|c|}{ 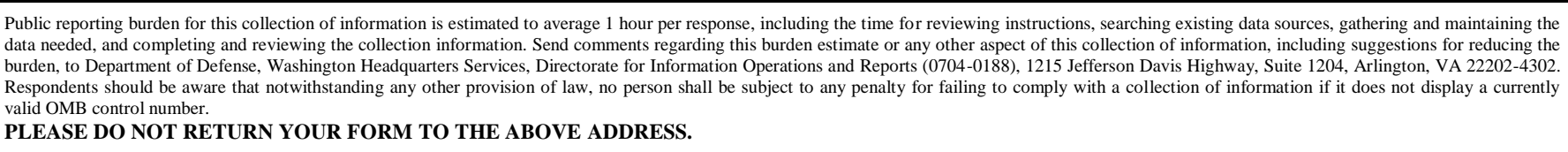 } \\
\hline $\begin{array}{l}\text { 1. REPORT DATE (DD-MM-YYYY) } \\
\text { July } 2013\end{array}$ & \begin{tabular}{|l|} 
2. REPORT TYPE \\
Final
\end{tabular} & 3. DATES COVERED (From - To) \\
\hline \multirow{3}{*}{\multicolumn{2}{|c|}{$\begin{array}{l}\text { 4. TITLE AND SUBTITLE } \\
\text { Monolithic Microwave Integrated Circuits (MMIC) Broadband Po } \\
\text { Amplifiers (Part 2) }\end{array}$}} & 5a. CONTRACT NUMBER \\
\hline & & 5b. GRANT NUMBER \\
\hline & & 5c. PROGRAM ELEMENT NUMBER \\
\hline \multirow{3}{*}{\multicolumn{2}{|c|}{$\begin{array}{l}\text { 6. AUTHOR(S) } \\
\text { John E. Penn }\end{array}$}} & 5d. PROJECT NUMBER \\
\hline & & 5e. TASK NUMBER \\
\hline & & 5f. WORK UNIT NUMBER \\
\hline \multicolumn{2}{|c|}{$\begin{array}{l}\text { 7. PERFORMING ORGANIZATION NAME(S) AND ADDRESS(ES) } \\
\text { U.S. Army Research Laboratory } \\
\text { ATTN: RDRL-SER-E } \\
\text { 2800 Powder Mill Road } \\
\text { Adelphi, MD 20783-1197 }\end{array}$} & $\begin{array}{l}\text { 8. PERFORMING ORGANIZATION } \\
\text { REPORT NUMBER } \\
\text { ARL-TN-0556 }\end{array}$ \\
\hline \multirow{2}{*}{\multicolumn{2}{|c|}{ 9. SPONSORING/MONITORING AGENCY NAME(S) AND ADDRESS(ES) }} & 10. SPONSOR/MONITOR'S ACRONYM(S) \\
\hline & & $\begin{array}{l}\text { 11. SPONSOR/MONITOR'S REPORT } \\
\text { NUMBER(S) }\end{array}$ \\
\hline \multicolumn{3}{|c|}{ 12. DISTRIBUTION/AVAILABILITY STATEMENT } \\
\hline \multicolumn{3}{|c|}{ Approved for public release; distribution unlimited. } \\
\hline
\end{tabular}

13. SUPPLEMENTARY NOTES

\section{ABSTRACT}

A broadband amplifier design approach for microwave monolithic integrated circuits (MMICs) was previously documented in a technical report, ARL-TR-6278, Monolithic Microwave Integrated Circuits (MMIC) Broadband Power Amplifiers,

December 2012. The three amplifier designs previously fabricated and tested as part of the fall 2011 Johns Hopkins University (JHU) MMIC Design Course, taught by the author, covered 2-6, 5-11, and $28 \mathrm{GHz}$. Since there was extra space available in the fall 2012 JHU MMIC Design Course fabrication, two additional amplifiers were designed, fabricated, and tested following the same design approach. This follow-up technical note documents the two recent amplifier designs, one was designed for 1-5 GHz operation and the second for 10-19 GHz operation.

\section{SUBJECT TERMS}

MMIC, broadband, power amplifier, GaAs

\begin{tabular}{|c|c|c|c|c|c|}
\hline \multicolumn{3}{|c|}{ 16. SECURITY CLASSIFICATION OF: } & \multirow{2}{*}{$\begin{array}{l}\text { 17. LIMITATION } \\
\text { OF } \\
\text { ABSTRACT } \\
\text { UU }\end{array}$} & \multirow{2}{*}{$\begin{array}{l}\text { 18. NUMBER } \\
\text { OF } \\
\text { PAGES } \\
20\end{array}$} & $\begin{array}{l}\text { 19a. NAME OF RESPONSIBLE PERSON } \\
\text { John E. Penn }\end{array}$ \\
\hline $\begin{array}{l}\text { a. REPORT } \\
\text { Unclassified }\end{array}$ & $\begin{array}{l}\text { b. ABSTRACT } \\
\text { Unclassified }\end{array}$ & $\begin{array}{l}\text { c. THIS PAGE } \\
\text { Unclassified }\end{array}$ & & & $\begin{array}{l}\text { 19b. TELEPHONE NUMBER (Include area code) } \\
\text { (301) 394-0423 }\end{array}$ \\
\hline
\end{tabular}




\section{Contents}

List of Figures $\quad$ iv

List of Tables $\quad$ iv

$\begin{array}{lc}\text { Acknowledgments } & \text { v }\end{array}$

$\begin{array}{ll}\text { 1. Introduction } & 1\end{array}$

2. Design Approach $\quad 1$

3. A 1-5 GHz Broadband Power Amplifier 1

4. A 10-19 GHz Broadband Power Amplifier 6

$\begin{array}{ll}\text { 5. Conclusion } & 10\end{array}$

$\begin{array}{ll}\text { List of Symbols, Abbreviations, and Acronyms } & 11\end{array}$

$\begin{array}{ll}\text { Distribution List } & 12\end{array}$ 


\section{List of Figures}

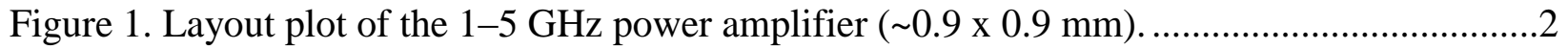

Figure 2. A 2-GHz load-pull simulation of output power (Pcomp-6 x $65 \mu \mathrm{m}$ PHEMT).............2

Figure 3. A 2-GHz load-pull simulation of PAE (6 x 65 m m PHEMT). ....................................3

Figure 4. MMIC 1-5 GHz broadband power amplifier linear simulations versus measured (solid).

Figure 5. MMIC 1-5 GHz output power and PAE performance simulation $(1,2,3$, and 4 $\mathrm{GHz})$

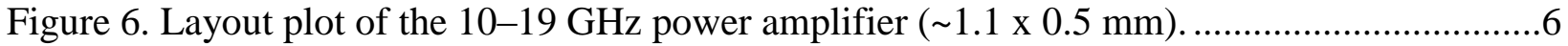

Figure 7. A 16-GHz load-pull simulation of output power (Pcomp-6 x 50 m PHEMT). ...........7

Figure 8. A 16-GHz load-pull simulation of PAE (6 x $50 \mu \mathrm{m}$ PHEMT). .................................7

Figure 9. MMIC 10-19 GHz broadband power amplifier linear simulations vs. measured (solid).

Figure 10. MMIC 10-19 GHz output power and PAE performance simulation $(14,16$, and 18 $\mathrm{GHz})$

\section{List of Tables}

Table 1. Power performance for the $1-5 \mathrm{GHz}$ broadband amplifier. ........................................5

Table 2. Power performance for the 10-19 GHz broadband amplifier. 


\section{Acknowledgments}

Once again, I would like to acknowledge the support of the U.S. Army Research Laboratory (ARL) in supporting my part-time passion of teaching the Johns Hopkins University (JHU) Monolithic Microwave Integrated Circuit (MMIC) Design Course, as well as TriQuint Semiconductor for fabricating designs for JHU students since 1989. Software support for these JHU designs is provided by Applied Wave Research (AWR), Agilent, Inc., and Sonnet Software. 
INTENTIONALLY LEFT BLANK. 


\section{Introduction}

Amplifier design is a tradeoff of gain, bandwidth, noise performance, power performance, efficiency, stability, and impedance match. The following broadband amplifier design approach emphasizes good output power and efficiency, with broadband gain and match. Previously, three amplifier designs were fabricated in TriQuint Semiconductor's 0.13- $\mu \mathrm{m}$ TQP13 gallium arsenide (GaAs) process and tested as part of the fall 2011 Johns Hopkins University (JHU) Monolithic Microwave Integrated Circuit (MMIC) Design Course, taught by the author, covering 2-6, 5-11, and $28 \mathrm{GHz}$. Since there was extra space available in the fall 2012 JHU MMIC Design Course fabrication, two additional amplifiers using the TQP13 process were designed, fabricated, and tested following the same broadband power amplifier design approach. One amplifier was designed for a lower band of $1-5 \mathrm{GHz}$ operation, while the second was designed for $10-19 \mathrm{GHz}$ operation.

\section{Design Approach}

The design approach follows the double "Q" output matching described in ARL-TR-62781. After designing the broadband output match for good efficiency and bandwidth, a simple high-pass, low-pass (HP/LP) input match is used to achieve good return loss across the full bandwidth, which is constrained by the transistor's parasitics. Simulations using Microwave Office (MWO) with the TriQuint TQP13 0.13- $\mu \mathrm{m}$ pseudomorphic high electron mobility transistor (PHEMT) process are shown for each of the two amplifier designs.

\section{A 1-5 GHz Broadband Power Amplifier}

The broadband design approach was used for an amplifier centered at $2 \mathrm{GHz}$. Figure 1 shows the layout of the 1-5 GHz amplifier. A simple low-pass input match consisting of a shunt capacitor and series inductor provided a compromise with fair input return loss and broadband gain. This design used a 6 x $65 \mu \mathrm{m}$ PHEMT, instead of the standard $6 \times 50 \mu \mathrm{m}$ PHEMT used in the other broadband designs. A compromise was struck between the best output power and best efficiency using the nonlinear model for load-pull equivalent simulations (figures 2 and 3). Best output match was chosen as $65 \Omega$ in parallel with $184 \mathrm{fF}$, for a "Q" of 0.2 . Using the two load contour simulations, this output match should yield $20.8 \mathrm{dBm}$ of output power at $61 \%$ power-added

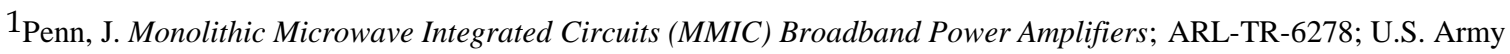
Research Laboratory: Adelphi, MD, December 2012.
} 
efficiency (PAE) (2 GHz). This estimate uses the TQP13 TOM4 nonlinear model biased at $4 \mathrm{~V}$ DC with ideal lossless matching elements.

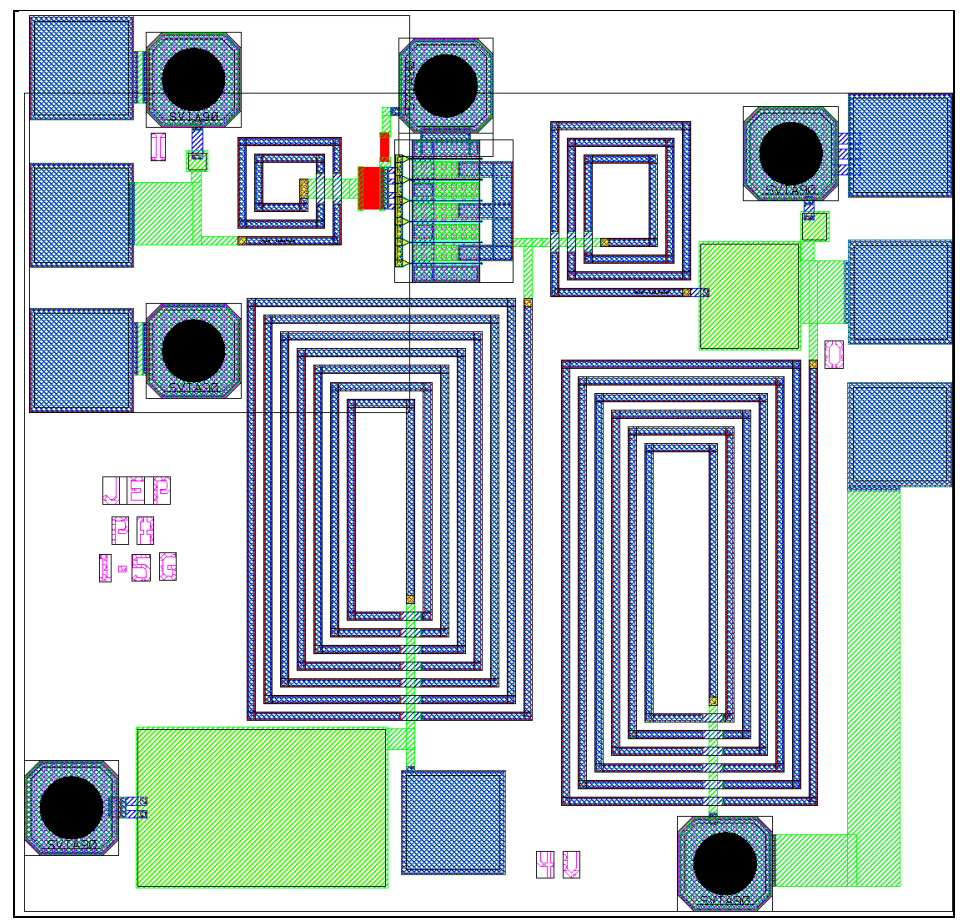

Figure 1. Layout plot of the $1-5 \mathrm{GHz}$ power amplifier $(\sim 0.9 \times 0.9 \mathrm{~mm})$.

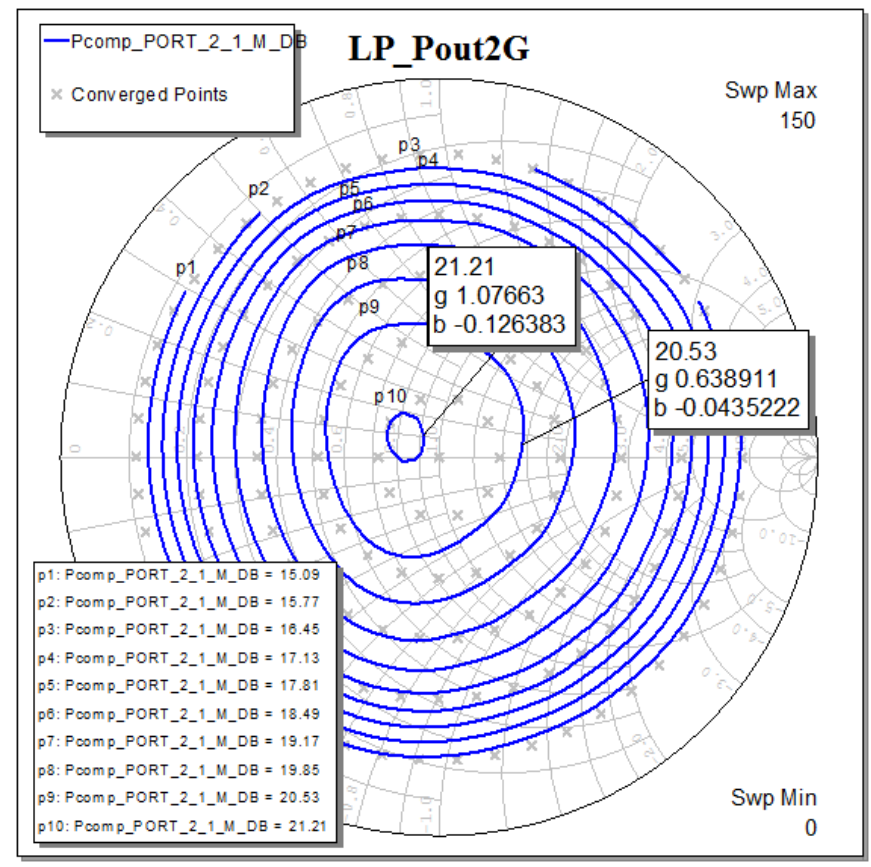

Figure 2. A 2-GHz load-pull simulation of output power (Pcomp-6 x $65 \mu \mathrm{m}$ PHEMT). 


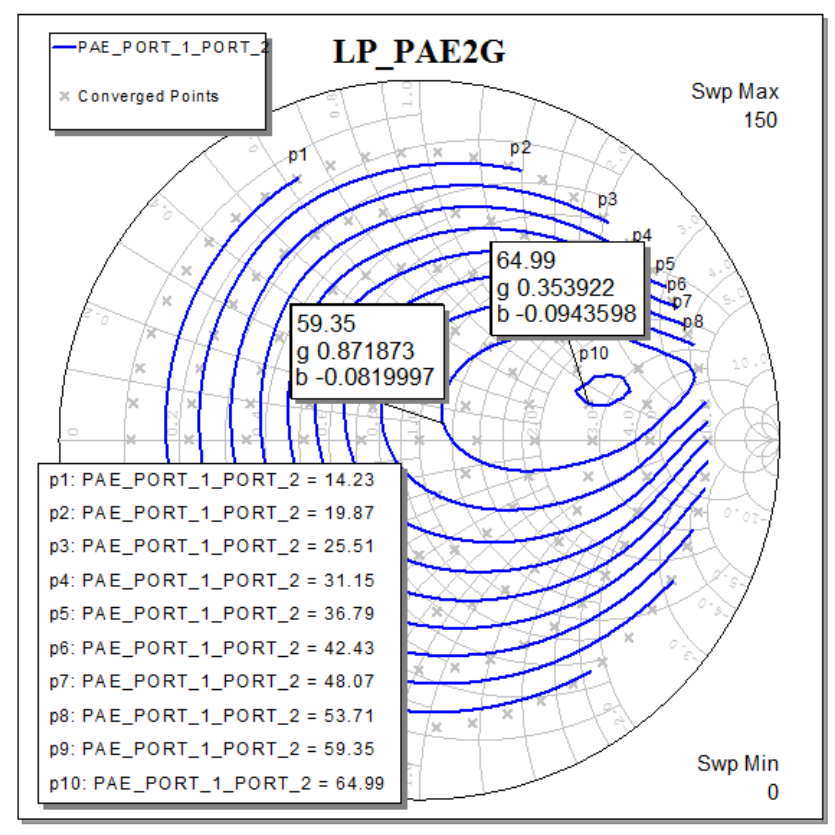

Figure 3. A 2-GHz load-pull simulation of PAE (6 x $65 \mu \mathrm{m}$ PHEMT).

After designing the stabilizing network, input matching network, and output matching network using TriQuint library elements, the final layout is simulated with MWO to predict the Sparameter performance. Additional Sonnet EM simulations of the actual layouts were also performed, which were similar to the linear MWO simulations with a slight "typical" down-shift in frequency performance. Figure 4 shows the actual measured results (solid) versus the linear MWO simulations (dot-dash) and the Sonnet EM simulations (dotted). For this example, the measurements appear to be in closer agreement to the original MWO linear simulations. Both simulations agree well with the measurements.

A nonlinear simulation of the 1-5 GHz MMIC for expected output power and PAE at 1, 2, 3, and $4 \mathrm{GHz}$ predicts better than $20.9 \mathrm{dBm}$ of output power $(120 \mathrm{~mW})$ and greater than $46 \%$ PAE, with a peak of $54 \% \mathrm{PAE}$ at $2 \mathrm{GHz}$ (figure 5). Gain falls off with increasing frequency for GaAs PHEMTs, so for each of these broadband designs, the higher gains are at the lower end of the operating band.

Actual measured performance at 1,2,3,4, and $5 \mathrm{GHz}$ is shown in table 1 . The output power (Pout(corr)) and PAE were lower than predicted, but consistent with the previous designs. Best output power was about $19 \mathrm{dBm}$ and $35 \% \mathrm{PAE}$ at 3 and $4 \mathrm{GHz}$ (4 V DC bias). 


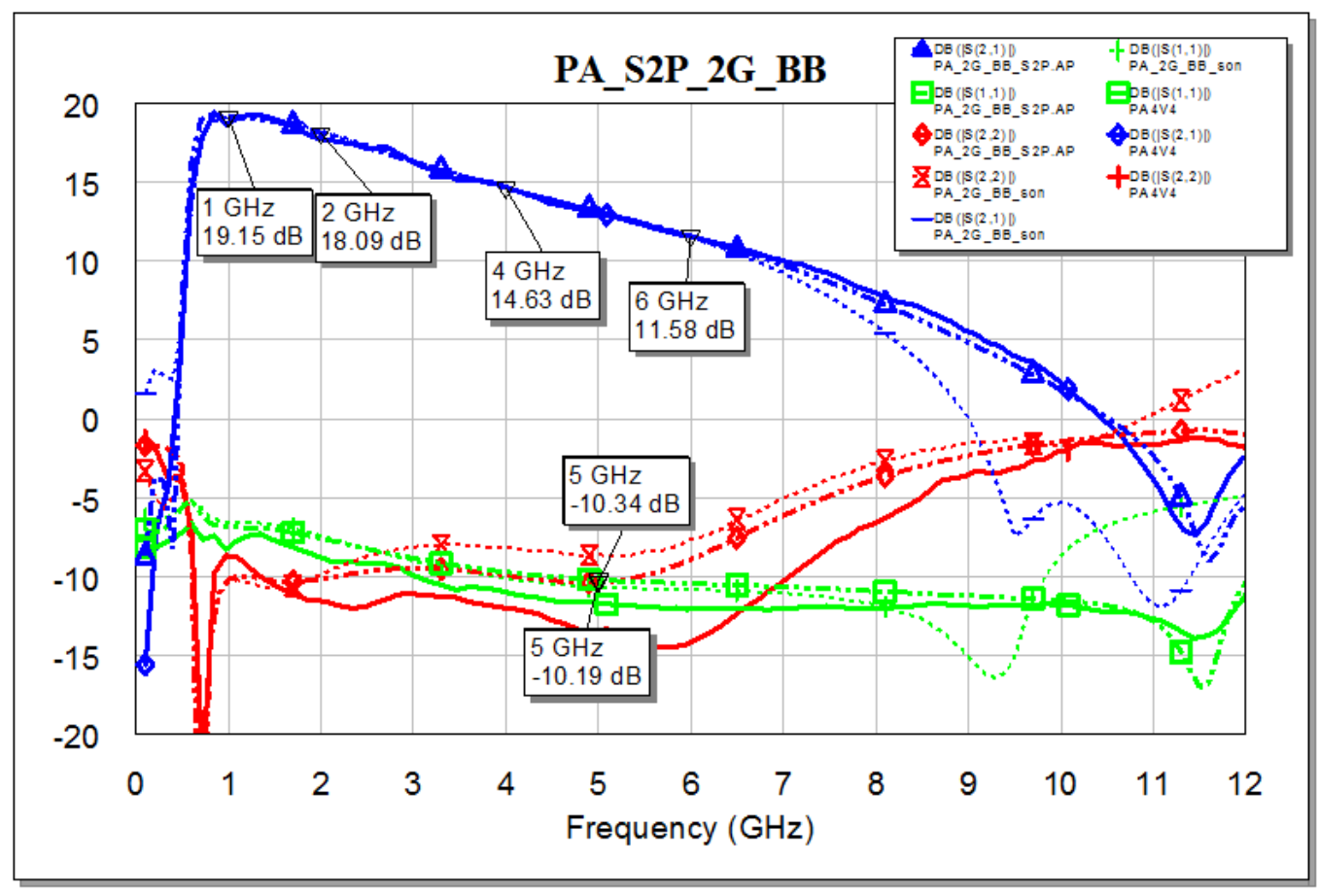

Figure 4. MMIC 1-5 GHz broadband power amplifier linear simulations versus measured (solid).

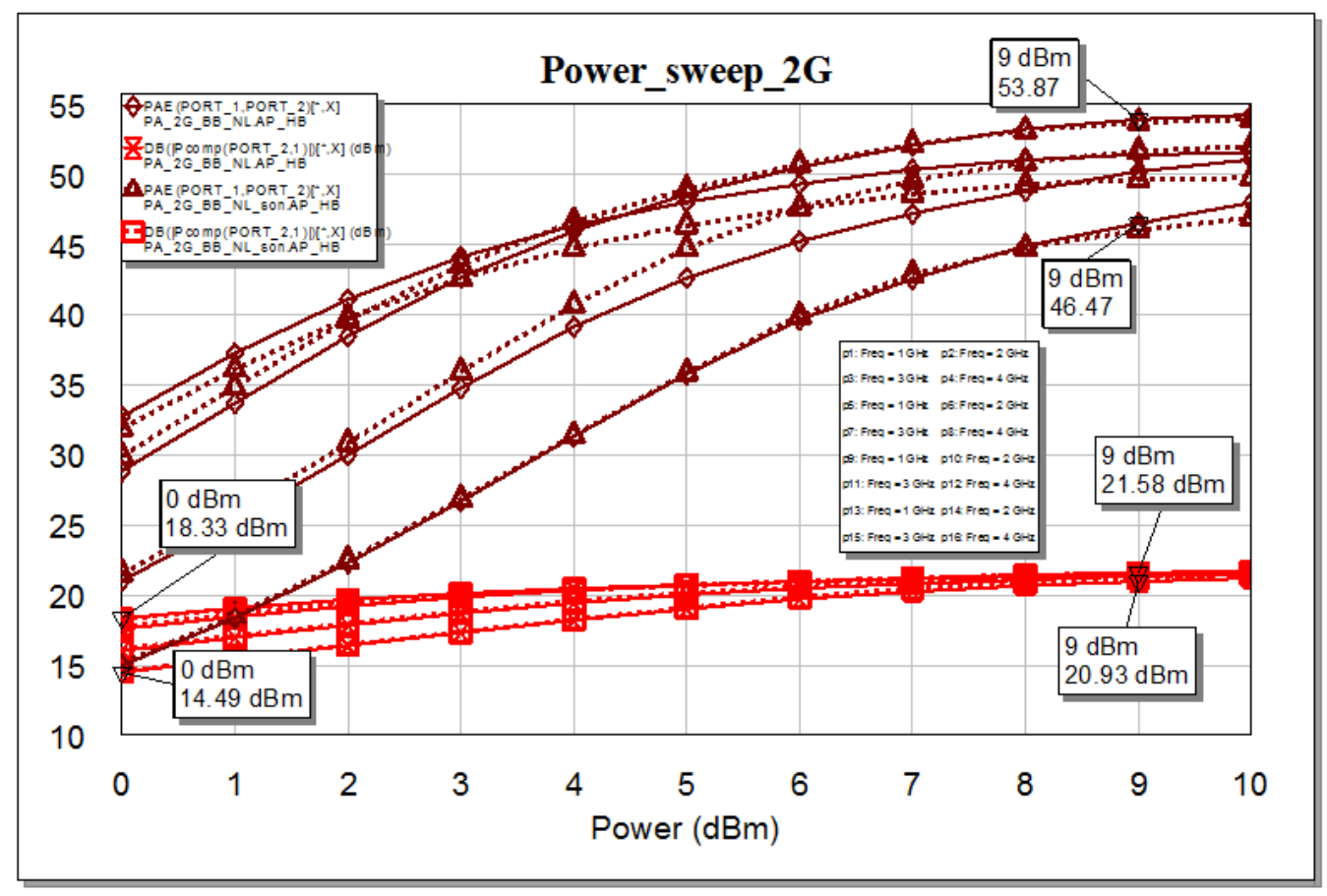

Figure 5. MMIC 1-5 GHz output power and PAE performance simulation (1, 2, 3, and $4 \mathrm{GHz})$. 
Table 1. Power performance for the $1-5 \mathrm{GHz}$ broadband amplifier.

\begin{tabular}{|c|c|c|c|c|c|c|c|c|c|}
\hline \multirow{2}{*}{$\begin{array}{l}1 \mathrm{GHz} \\
\operatorname{Pin}(\mathrm{SG})\end{array}$} & \multirow{2}{*}{$\begin{array}{l}\text { Die\#1 } \\
\text { Pout(SA) } \\
\end{array}$} & \multicolumn{3}{|c|}{ 1-5 GHz Fall12 TQP13 } & \multirow[b]{2}{*}{ I1(4V) } & \multirow{2}{*}{$\begin{array}{l}4 \mathrm{~V} ; 53 \mathrm{~mA} \\
\mathbf{P D C}(\mathbf{m w})\end{array}$} & \multirow[b]{2}{*}{ Pout(mw) } & \multirow[b]{2}{*}{ Drn Eff } & \multirow[b]{2}{*}{ PAE } \\
\hline & & Pin(corr) & Pout(corr) & Gain & & & & & \\
\hline-10.0 & 7.78 & -10.60 & 8.38 & 18.98 & 53 & 212.0 & 6.89 & 3.2 & 3.2 \\
\hline-5.0 & 12.77 & -5.60 & 13.37 & 18.97 & 53 & 212.0 & 21.73 & 10.2 & 10.1 \\
\hline-2.0 & 15.36 & -2.60 & 15.96 & 18.56 & 53 & 212.0 & 39.45 & 18.6 & 18.3 \\
\hline 0.0 & 16.70 & -0.60 & 17.30 & 17.90 & 53 & 212.0 & 53.70 & 25.3 & 24.9 \\
\hline 2.0 & 17.45 & 1.40 & 18.05 & 16.65 & 53 & 212.0 & 63.83 & 30.1 & 29.5 \\
\hline 4.0 & 17.76 & 3.40 & 18.36 & 14.96 & 53 & 212.0 & 68.55 & 32.3 & 31.3 \\
\hline
\end{tabular}

\begin{tabular}{|c|c|c|c|c|c|c|c|c|c|}
\hline \multirow{2}{*}{\begin{tabular}{|l}
$2 \mathrm{GHz}$ \\
$\operatorname{Pin}(\mathrm{SG})$ \\
\end{tabular}} & \multirow{2}{*}{$\begin{array}{l}\text { Die\#1 } \\
\text { Pout(SA) }\end{array}$} & \multicolumn{3}{|c|}{ 1-5 GHz Fall12 TQP13 } & \multirow[b]{2}{*}{ I1(4V) } & \multicolumn{2}{|l|}{$4 \mathrm{~V} ; 53 \mathrm{~mA}$} & \multirow[b]{2}{*}{ Drn Eff } & \multirow[b]{2}{*}{ PAE } \\
\hline & & Pin(corr) & Pout(corr) & Gain & & PDC(mw) & Pout(mw) & & \\
\hline-10.0 & 6.13 & -10.90 & 7.03 & 17.93 & 53 & 212.0 & 5.05 & 2.4 & 2.3 \\
\hline-5.0 & 11.19 & -5.90 & 12.09 & 17.99 & 53 & 212.0 & 16.18 & 7.6 & 7.5 \\
\hline-2.0 & 14.09 & -2.90 & 14.99 & 17.89 & 53 & 212.0 & 31.55 & 14.9 & 14.6 \\
\hline 0.0 & 15.75 & -0.90 & 16.65 & 17.55 & 53 & 212.0 & 46.24 & 21.8 & 21.4 \\
\hline 2.0 & 16.91 & 1.10 & 17.81 & 16.71 & 53 & 212.0 & 60.39 & 28.5 & 27.9 \\
\hline 4.0 & 17.41 & 3.10 & 18.31 & 15.21 & 53 & 212.0 & 67.76 & 32.0 & 31.0 \\
\hline
\end{tabular}

\begin{tabular}{|l|l|l|l|l}
\hline $3 \mathrm{GHz}$ & Die\#1 & 1-5 GHz Fall12 TQP13 & 4V ; $53 \mathrm{~mA}$
\end{tabular}

$\begin{array}{llllll}\text { Pin(SG) } & \text { Pout(SA) Pin(corr) } & \text { Pout(corr) Gain } \quad \text { I1(4V) } & \text { PDC(mw) Pout(mw) Drn Eff } & \text { PAE }\end{array}$

\begin{tabular}{|r|r|r|r|r|r|r|r|r|r|r|}
\hline-2.0 & 12.41 & -3.05 & 13.46 & 16.51 & 53 & 212.0 & 22.18 & 10.5 & 10.2 \\
\hline 0.0 & 14.33 & -1.05 & 15.38 & 16.43 & 53 & 212.0 & 34.51 & 16.3 & 15.9 \\
\hline 2.0 & 16.02 & 0.95 & 17.07 & 16.12 & 53 & 212.0 & 50.93 & 24.0 & 23.4 \\
\hline 4.0 & 17.21 & 2.95 & 18.26 & 15.31 & 53 & 212.0 & 66.99 & 31.6 & 30.7 \\
\hline 5.0 & 17.56 & 3.95 & 18.61 & 14.66 & 53 & 212.0 & 72.61 & 34.3 & 33.1 \\
\hline 6.0 & 17.80 & 4.95 & 18.85 & 13.90 & 53 & 212.0 & 76.74 & 36.2 & $\mathbf{3 4 . 7}$ \\
\hline
\end{tabular}

\begin{tabular}{|r|r|r|r|r|r|r|r|r|r|r|}
\hline 4 GHz & \multicolumn{3}{l}{ Die\#1 } & \multicolumn{3}{l|}{ 1-5 GHz Fall12 TQP13 } & \multicolumn{2}{l|}{ 4V ; 53 mA } & \\
\hline Pin(SG) & Pout(SA) & Pin(corr) & Pout(corr) Gain & I1(4V) & \multicolumn{1}{l|}{ PDC(mw) } & Pout(mw) & Drn Eff & PAE \\
\hline 0.0 & 11.59 & -1.35 & 12.94 & 14.29 & 53 & 212.0 & 19.68 & 9.3 & 8.9 \\
\hline 2.0 & 14.14 & 0.65 & 15.49 & 14.84 & 53 & 212.0 & 35.40 & 16.7 & 16.2 \\
\hline 4.0 & 15.88 & 2.65 & 17.23 & 14.58 & 53 & 212.0 & 52.84 & 24.9 & 24.1 \\
\hline 5.0 & 16.57 & 3.65 & 17.92 & 14.27 & 53 & 212.0 & 61.94 & 29.2 & 28.1 \\
\hline 6.0 & 17.15 & 4.65 & 18.50 & 13.85 & 53 & 212.0 & 70.79 & 33.4 & 32.0 \\
\hline 7.0 & 17.62 & 5.65 & $\mathbf{1 8 . 9 7}$ & $\mathbf{1 3 . 3 2}$ & 53 & 212.0 & 78.89 & 37.2 & $\mathbf{3 5 . 5}$ \\
\hline
\end{tabular}

\begin{tabular}{|c|c|c|c|c|c|c|c|c|c|}
\hline \multirow{2}{*}{$\begin{array}{l}5 \mathrm{GHz} \\
\operatorname{Pin}(\mathrm{SG})\end{array}$} & \multirow{2}{*}{$\begin{array}{l}\text { Die\#1 } \\
\text { Pout(SA) }\end{array}$} & \multicolumn{3}{|c|}{ 1-5 GHz Fall12 TQP13 } & \multicolumn{3}{|c|}{$4 \mathrm{~V} ; 53 \mathrm{~mA}$} & \multirow[b]{2}{*}{ Drn Eff } & \multirow[b]{2}{*}{ PAE } \\
\hline & & Pin(corr) & Pout(corr) & Gain & I1(4V) & PDC(mw) & Pout(mw) & & \\
\hline 0.0 & 10.16 & -1.60 & 11.76 & 13.36 & 53 & 212.0 & 15.00 & 7.1 & 6.7 \\
\hline 2.0 & 12.46 & 0.40 & 14.06 & 13.66 & 53 & 212.0 & 25.47 & 12.0 & 11.5 \\
\hline 4.0 & 14.22 & 2.40 & 15.82 & 13.42 & 53 & 212.0 & 38.19 & 18.0 & 17.2 \\
\hline 6.0 & 15.56 & 4.40 & 17.16 & 12.76 & 53 & 212.0 & 52.00 & 24.5 & 23.2 \\
\hline 7.0 & 16.13 & 5.40 & 17.73 & 12.33 & 53 & 212.0 & 59.29 & 28.0 & 26.3 \\
\hline 8.0 & 16.62 & 6.40 & 18.22 & 11.82 & 53 & 212.0 & 66.37 & 31.3 & 29.2 \\
\hline
\end{tabular}




\section{A 10-19 GHz Broadband Power Amplifier}

The broadband design approach was used for an amplifier centered at $16 \mathrm{GHz}$. Figure 6 shows the layout of the 10-19 GHz amplifier. A simple HP/LP input match provided good input return loss and broadband gain. This design used the nominal 6 x $50 \mu \mathrm{m}$ PHEMT. A compromise was struck between the best output power and best efficiency using the nonlinear load-pull contour simulations (figures 7 and 8). Best output match was chosen as $70 \Omega$ in parallel with $165 \mathrm{fF}$, for a "Q" of 1.2. Using the two performance load contours, this output match should yield $20.0 \mathrm{dBm}$ of output power at $45 \%$ PAE $(16 \mathrm{GHz})$. This estimate uses the TQP13 TOM4 nonlinear model biased at $4 \mathrm{~V}$ DC with ideal lossless matching elements.

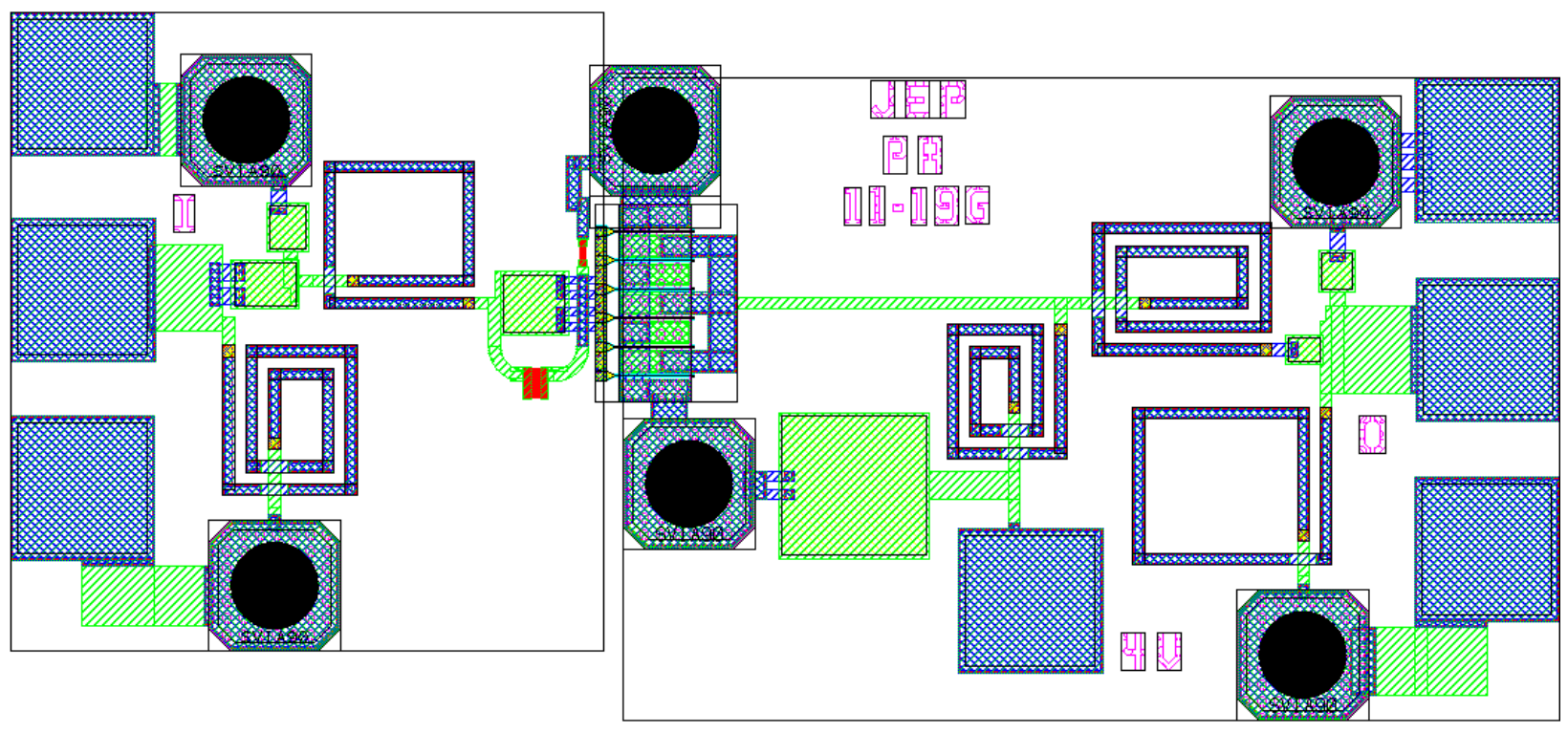

Figure 6. Layout plot of the 10-19 GHz power amplifier ( 1.1 x $0.5 \mathrm{~mm})$. 


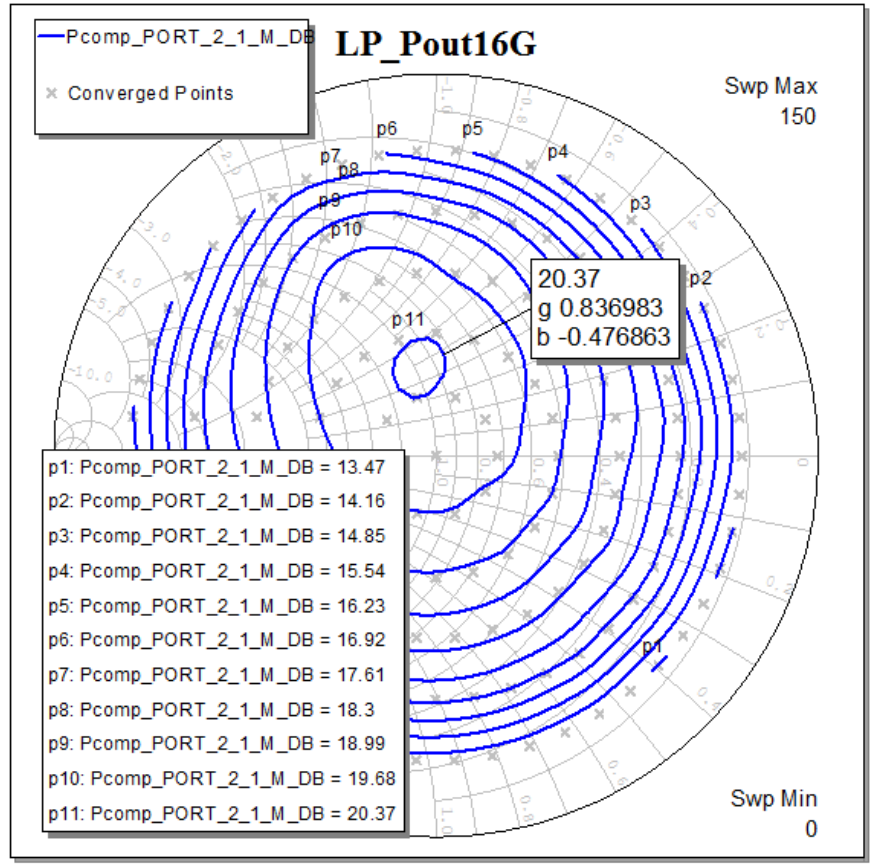

Figure 7. A 16-GHz load-pull simulation of output power (Pcomp-6 x $50 \mu \mathrm{m}$ PHEMT).

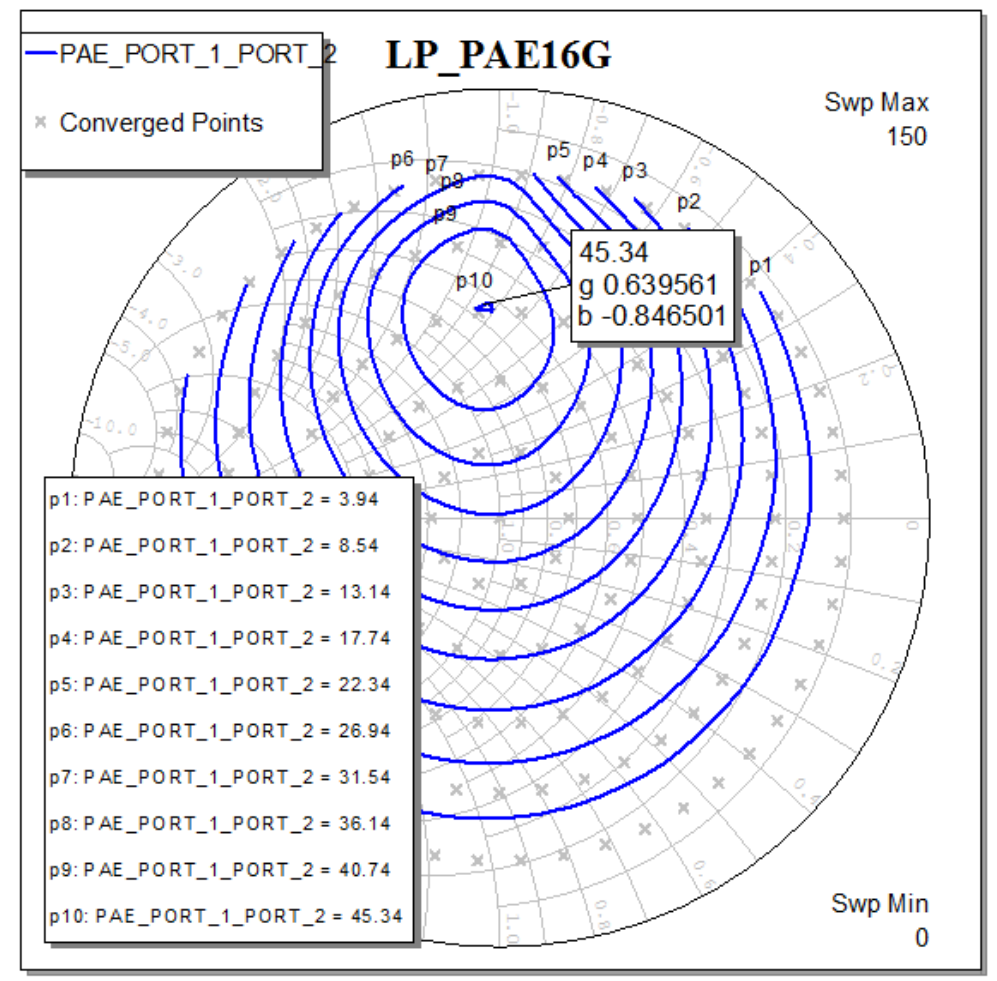

Figure 8. A 16-GHz load-pull simulation of PAE (6 x $50 \mu \mathrm{m}$ PHEMT). 
After designing the stabilizing network, input matching network, and output matching network using TriQuint library elements, the final layout is simulated with MWO to predict the Sparameter performance. Additional Sonnet EM simulations of the actual layouts were also performed, which were similar to the linear MWO simulations with a slight "typical" down-shift in frequency performance. Figure 9 shows the actual measured results (solid) versus the linear MWO simulations (dot-dash) and the Sonnet EM simulations (dotted). For this example, the measurements appear to be in closer agreement to the MWO linear simulations. Both simulations agree well with the measured performance.

A nonlinear simulation of the 10-19 GHz MMIC for expected output power and PAE at 14, 16, and $18 \mathrm{GHz}$ (figure 10) predicts better than $20.9 \mathrm{dBm}$ of output power $(120 \mathrm{~mW})$ and $32 \%$ to $39 \%$ PAE. Gain falls off with increasing frequency for GaAs PHEMTs, so with each of these broadband designs, the higher gains are at the lower frequency of the operating band.

Actual measured performance at 12,14 , and $16 \mathrm{GHz}$ is shown in table 2 . The output power (Pout(corr)) and PAE were lower than predicted, however the amplifier was not driven to its peak performance during testing. Best output power was about $18.4 \mathrm{dBm}$ and 33\% PAE at $14 \mathrm{GHz}$ and $1.5 \mathrm{~dB}$ compression (4 V DC Bias).

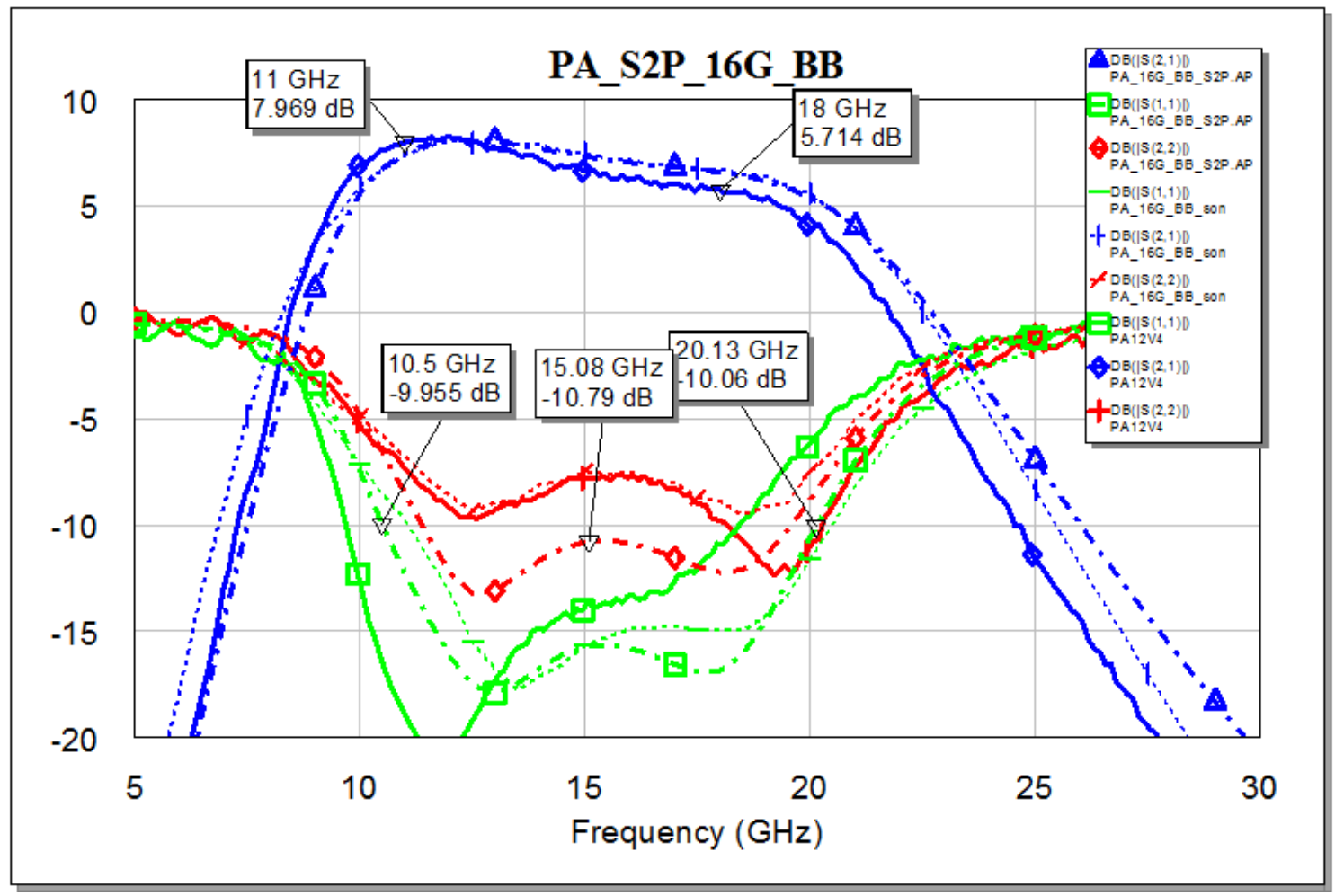

Figure 9. MMIC 10-19 GHz broadband power amplifier linear simulations vs. measured (solid). 


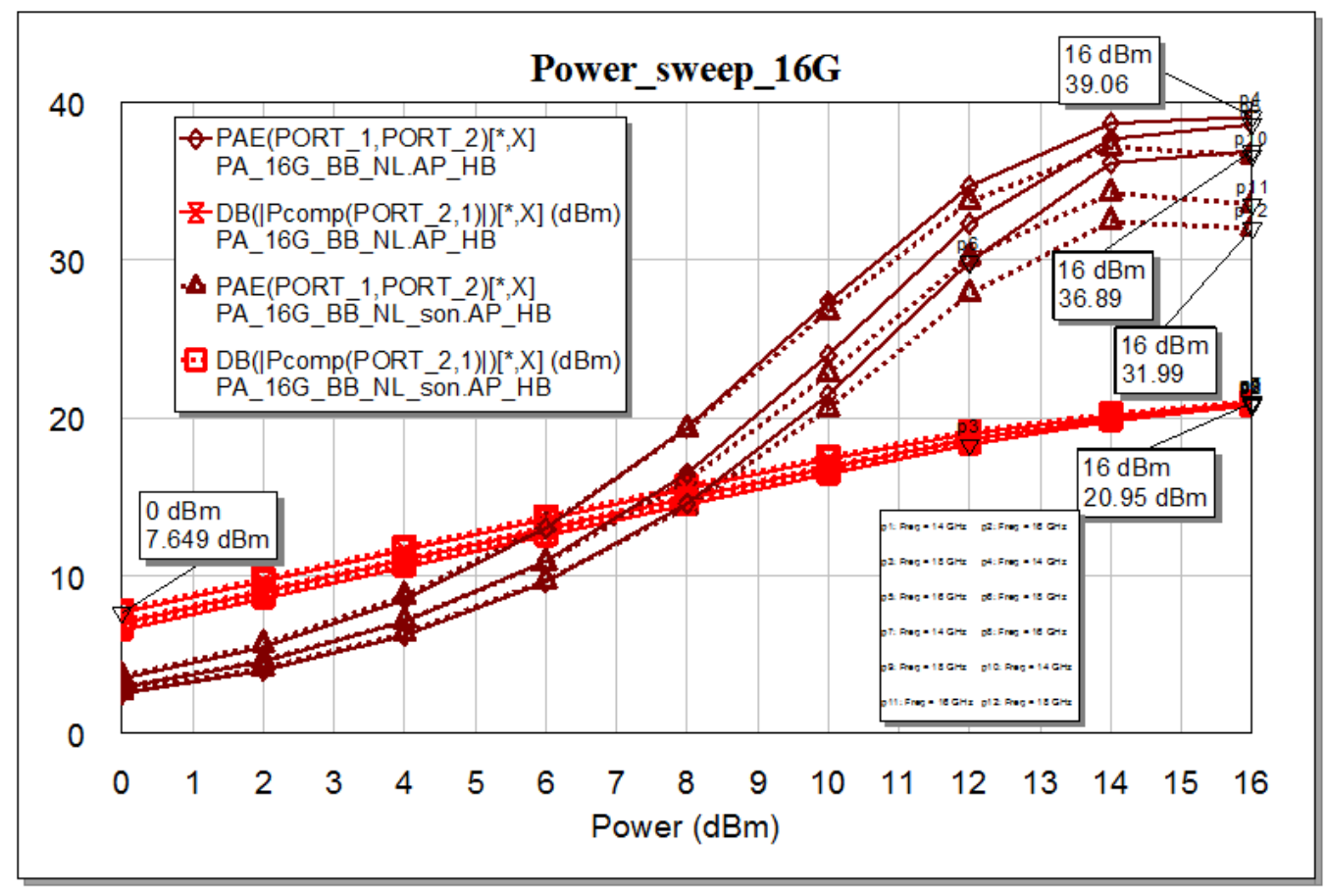

Figure 10. MMIC 10-19 GHz output power and PAE performance simulation (14, 16, and $18 \mathrm{GHz})$.

Table 2. Power performance for the 10-19 GHz broadband amplifier.

\begin{tabular}{|c|c|c|c|c|c|c|c|c|c|}
\hline $12 \mathrm{GHz}$ & Die\#1 & $11-19 \mathrm{GH}$ & z Fall12 TQP & P13 & & $4 \mathrm{~V} ; 45 \mathrm{~mA}$ & & & \\
\hline $\operatorname{Pin}(\mathrm{SG})$ & Pout(SA) & Pin(corr) & Pout(corr) & r) Gain & I1(4V) & PDC(mw) & Pout(mw) & Drn Eff & PAE \\
\hline-5.0 & -1.32 & -7. & 1.08 & 8.48 & 4 & 180.0 & 1.28 & 0.7 & 0.6 \\
\hline 0.0 & 3.6 & -2. & 6.07 & 8.47 & 4 & 180.0 & 4.05 & 2.2 & 1.9 \\
\hline 5.0 & 8.7 & 2.6 & 11.11 & 8.51 & 4 & 180.0 & 12.91 & 7.2 & 6.2 \\
\hline 10.0 & 13.3 & 7.6 & 15.75 & 8.15 & 4 & 180.0 & 37.58 & 20.5 & 17.7 \\
\hline 12.0 & 14.66 & 9.6 & 17.06 & 7.46 & 4 & 188.0 & 50.82 & 27. & 22.2 \\
\hline 14.0 & 15.4 & 11.6 & 17.83 & 6.23 & 4 & 168.0 & 60.67 & 36. & 27.5 \\
\hline $14 \mathrm{GHz}$ & Die\#1 & $11-19 \mathrm{GHz}$ & Fall12 TQP & P13 & & $4 \mathrm{~V} ; 45 \mathrm{~mA}$ & & & \\
\hline Pin(SG) & Pout(SA) & Pin(corr) & Pout(corr) & Gain & I1(4V) & PDC(mw) & Pout(mw) & Drn Eff & PAE \\
\hline-5.0 & -1.89 & -7.75 & 0.86 & 8.61 & $4 !$ & 180.0 & 1.22 & 0.7 & 0.6 \\
\hline 0.0 & 3.09 & -2.75 & 5.84 & 8.59 & $4 !$ & 180.0 & 3.84 & 2.1 & 1.8 \\
\hline 5.0 & 8.15 & 2.25 & 10.90 & 8.65 & 45 & 180.0 & 12.30 & 6.8 & 5.9 \\
\hline 10.0 & 13.00 & 7.25 & 15.75 & 8.50 & 45 & 180.0 & 37.58 & 20.9 & 17.9 \\
\hline 12.0 & 14.58 & 9.25 & 17.33 & 8.08 & 47 & 188.0 & 54.08 & 28.8 & 24.3 \\
\hline 14.0 & 15.61 & 11.25 & 18.36 & 7.11 & 42 & 168.0 & 68.55 & 40.8 & 32.9 \\
\hline $16 \mathrm{GHz}$ & Die\#1 & $11-19 \mathrm{GHz}$ & Fall12 TQP & P13 & & $4 \mathrm{~V} ; 45 \mathrm{~mA}$ & & & \\
\hline $\operatorname{Pin}(\mathrm{SG})$ & Pout(SA) & Pin(corr) & Pout(corr) & Gain & I1(4V) & PDC(mw) & Pout(mw) & Drn Eff & PAE \\
\hline-5.0 & -3.23 & -7.90 & -0.33 & 7.57 & 45 & 180.0 & 0.93 & 0.5 & 0.4 \\
\hline 0.0 & 1.73 & -2.90 & 4.63 & 7.53 & 45 & 180.0 & 2.90 & 1.6 & 1.3 \\
\hline 5.0 & 6.77 & 2.10 & 9.67 & 7.57 & 45 & 180.0 & 9.27 & 5.1 & 4.2 \\
\hline 10.0 & 11.76 & 7.10 & 14.66 & 7.56 & 45 & 180.0 & 29.24 & 16.2 & 13.4 \\
\hline 12.0 & 13.56 & 9.10 & 16.46 & 7.36 & 47 & 188.0 & 44.26 & 23.5 & 19.2 \\
\hline 14.0 & 14.92 & 11.10 & 17.82 & 6.72 & 42 & 168.0 & 60.53 & 36.0 & 28.4 \\
\hline
\end{tabular}




\section{Conclusion}

These broadband medium power amplifier MMICs were designed using some of the techniques taught by Dale Dawson in the JHU Power MMIC Course. Previously, 2-6 and 5-11 GHz broadband amplifiers were documented in technical report, ARL-TR-6278 (December 2012). These two additional designs documented here extend lower $(1-5 \mathrm{GHz})$ and higher $(10-19 \mathrm{GHz})$ in frequency. These broadband filter and matching techniques could be applied to parallel combinations of transistors to increase power, but these simple one-transistor, single-stage designs represent a proof of the design approach using actual fabricated and measured MMICs. It should be noted that these broadband techniques were also used to successfully design two high power broadband MMIC amplifiers at 3-5 and 4-6 GHz using TriQuint's 0.25- $\mu \mathrm{m}$ gallium nitride $(\mathrm{GaN}$ ) process (see ARL-TR-59872 and ARL-TR-60903). Other broadband amplifier designs of increasing difficulty are currently being designed at ARL, extending to higher frequencies, parallel combined output devices, and cascaded gain stages.

These simple one stage MMIC amplifiers illustrate a broadband design approach and the limitations that start with the device parasitics, the quality of the nonlinear and linear models available, and the quality of the MMIC fabrication process.

While these designs were part of a JHU course, the design techniques and Microwave MMICs would be of interest to Army and Department of Defense communications systems, sensors, and wireless systems.

\footnotetext{
${ }^{2}$ Penn, J. Broadband, Efficient, Linear C-Band Power Amplifiers designed in a 0.25- $\mu$ m Gallium Nitride (GaN) Foundry Process from TriQuint Semiconductor; ARL-TR-5987; U.S. Army Research Laboratory: Adelphi, MD, May 2012.

${ }^{3}$ Penn, J. Testing of Broadband, Efficient, Linear C-Band Power Amplifiers; ARL-TR-6090; U.S. Army Research Laboratory: Adelphi, MD, August 2012.
} 


\section{List of Symbols, Abbreviations, and Acronyms}

$\begin{array}{ll}\text { ARL } & \text { U.S. Army Research Laboratory } \\ \text { AWR } & \text { Applied Wave Research } \\ \text { GaAs } & \text { gallium arsenide } \\ \text { GaN } & \text { gallium nitride } \\ \text { HP } & \text { high-pass } \\ \text { JHU } & \text { Johns Hopkins University } \\ \text { LP } & \text { low-pass } \\ \text { MMIC } & \text { monolithic microwave integrated circuit } \\ \text { MWO } & \text { Microwave Office } \\ \text { PAE } & \text { power-added efficiency } \\ \text { PHEMT } & \text { pseudomorphic high electron mobility transistor }\end{array}$


NO. OF

COPIES ORGANIZATION

1 DEFENSE TECHNICAL

(PDF) INFORMATION CTR

DTIC OCA

2 DIRECTOR

(PDFS) US ARMY RESEARCH LAB

RDRL CIO LL

IMAL HRA MAIL \& RECORDS MGMT

1 GOVT PRINTG OFC

(PDFS) A MALHOTRA

4 DIRECTOR

(PDFS) US ARMY RESEARCH LAB

4 RDRL SER

(HCS) PAUL AMIRTHARAJ (PDF)

RDRL SER E

ROMEO DEL ROSARIO (1 HC)

JAMES WILSON (PDF)

JOHN PENN (3 HCS)

ROBERT PROIE (PDF)

ED VIVEIROS (PDF) 